\title{
Eluição de fósforo em relação ao tempo de difusão em colunas com agregados de um Latossolo Vermelho distrófico
}

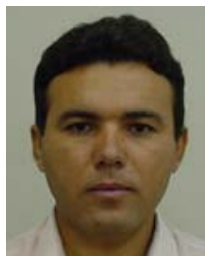

\author{
Cícero A. de S. Araújo을 Hugo A. Ruiz ${ }^{3}$, Davi J. Silva ${ }^{4}$, Paulo A. Ferreira ${ }^{5}$, \\ Víctor H. A. V. ${ }^{6}$ \& Antonio F. de C. Bahia Filho ${ }^{7}$
}

1 Parte da Tese de Doutorado do primeiro autor, apresentada a Universidade Federal de Viçosa
2 Centro Federal de Educação Tecnológica de Petrolina. CEP 56.314-520, Petrolina, PE. Fone: (87) 3863-2330.
E-mail: casa@cefetpet.br (Foto)
3 UFV/DPS. CEP 36571-O00, Viçosa, MG. Fone: (31) 3899-1052. E-mail: hruiz@mail.ufv.br
${ }^{4}$ Embrapa Semi-Árido. CEP 56300-970, Petrolina, PE. Fone: (87) 3762-1711. E-mail: davi@cpatsa.embrapa.br
5 UFV/DEA. Fone: (31) 3899-1911. E-mail: pafonso@mail.ufv.br
6 UFV/DPS. Fone: (31) 3899-1061. E-mail: vhav@mail.ufv.br
7 Embrapa Milho e Sorgo. CEP 35701-970, Sete Lagoas, MG. Fone: (31) 3779-1000. E-mail: bahia@cnpms.embrapa.br

Protocolo 58 - 26/4/2002 - Aprovado em 13/2/2003

\begin{abstract}
Resumo: Com o objetivo de se quantificar o teor de fósforo no efluente de colunas com agregados de um Latossolo Vermelho distrófico em resposta ao tempo de difusão, realizou-se um experimento

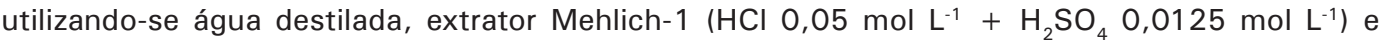
solução de acetato de amônio $0,1 \mathrm{~mol} \mathrm{~L}^{-1}$, a pH 7, como eluentes. Os tratamentos corresponderam a um arranjo fatorial $4 \times 5$, sendo quatro classes de agregados $(2,0-1,0 ; 1,0-0,5 ; 0,5-0,25$ e $0,25-0,105 \mathrm{~mm}$ ) e cinco tempos de difusão $(0,1,2,4$ e 6 dias). As colunas receberam um volume de eluente igual a dez vezes o seu volume de poros, recolhendo-se cinco frações de efluente, cada uma de dois volumes de poros. Nas unidades experimentais correspondentes ao tempo de difusão zero, o volume do líquido foi aplicado de uma só vez, enquanto nas restantes foram realizadas eluições com dois volumes de poros, nos intervalos indicados para cada tempo de difusão. A água destilada eluiu maior quantidade de fósforo dos agregados de menor tamanho e teve incrementada a quantidade do fósforo eluído com o tempo de difusão. 0 extrator Mehlich-1 eluiu de três a sessenta vezes mais fósforo que a água destilada, mostrando comportamento inverso ao da lixiviação com água, em relação à classe de agregados e ao tempo de contato. As quantidades de fósforo eluídas com solução de acetato de amônio foram tão pequenas que não atingiram a concentração mínima necessária para permitir sua detecção.
\end{abstract}

Palavras-chave: transporte de soluto, lixiviação, oxissolos

\section{Leaching of phosphorus in relation to diffusion time in columns with aggregates of a Rodhic Haplustox}

\begin{abstract}
This study quantified phosphorus in effluents of a Brazilian Rodhic Haplustox (Red Latosol) aggregates, in relation to diffusion time, using distilled water, Mehlich-1 extractor $(\mathrm{HCl}$ $\left.0.05 \mathrm{~mol} \mathrm{~L}^{-1}+\mathrm{H}_{2} \mathrm{SO}_{4} 0.0125 \mathrm{~mol} \mathrm{~L}^{-1}\right)$, and ammonium acetate $0.1 \mathrm{~mol} \mathrm{~L}^{-1}$ solution at $\mathrm{pH} 7$ as eluates. Treatments corresponded to a $4 \times 5$ factorial scheme: four aggregate classes (2.0-1.0, 1.0-0.5, 0.5-0.25, and 0.25-0.105 mm) and five diffusion times $(0,1,2,4$, and 6 days). The columns which corresponded to zero diffusion time received an eluate volume equal to ten times the pore volume, collected in five effluent fractions, each one with two pore-volumes. In the remaining experimental units, the elutions were accomplished with two pore-volumes at intervals indicated for each diffusion time. The distilled water leached greater amount of phosphorus from the smallest aggregates which increased with the increasing diffusion time. The Mehlich-1 extractor leached three to sixty times more phosphorus than the distilled water, showing a reverse behavior in relation to aggregate class and contact time. Phosphorus quantities leached with the ammonium acetate solution did not reach the minimum concentration required for detection.
\end{abstract}

Key words: solute transport, leachate, Latosol 


\section{INTRODUÇÃO}

Os Latossolos desenvolvidos nas áreas sob vegetação de cerrado apresentam, geralmente, estrutura formada de grânulos muito pequenos e, também, apreciáveis problemas de fertilidade. As limitações nutricionais estão associadas tanto à própria escassez de nutrientes, provocada pelo acentuado intemperismo, quanto às restrições no transporte dos nutrientes na solução do solo até as raízes das plantas. Neste caso, o suprimento de fósforo para as plantas não é influenciado apenas pelos fatores intensidade (I) e quantidade (Q) e sua relação (fator capacidade tampão $=\Delta \mathrm{I} / \Delta \mathrm{Q}$ ) mas, também, pelo seu transporte na solução do solo (Passioura, 1971).

Sem condições de estabelecer limites precisos, pode-se considerar duas regiões distintas na solução do solo, em que na primeira, denominada solução móvel, os solutos são transportados, essencialmente, por fluxo de massa; já na segunda, chamada imóvel, o transporte dos solutos se dá por difusão. A transferência de solutos entre essas duas regiões, por difusão, é proporcional à diferença de concentração entre a solução móvel e a imóvel (van Genuchten \& Wierenga, 1976; Rao et al., 1980).

Nos Latossolos, a região de solução móvel está associada à porosidade interagregados, onde cresce, praticamente, a totalidade do sistema radical. A solução imóvel ocupa o espaço poroso intra-agregado e, por estar retida com maior energia, encontra-se menos disponível às plantas. Rao et al. (1980) descreveram a transferência de solutos não-adsorvidos entre os espaços intra e interagregados, por três equações diferenciais, cujas soluções analíticas originaram os denominados modelos I e II para transporte de solutos entre as regiões de solução móvel e imóvel.

Gupta et al. (1999) verificaram a ocorrência de fluxo preferencial de fósforo em monólitos de solo que aumentou o fluxo de massa 2 a 3 vezes com relação ao transporte de massa estimado na ausência de fluxo preferencial. Este deve ocorrer na região de solução móvel do solo.

A interação do fósforo $(\mathrm{P})$ com o solo ocorre em duas etapas: uma instantânea e outra dependente de tempo. As reações instantâneas são atenuadas por aplicação prévia de fósforo, ao contrário daquelas dependentes de tempo. O tamanho dos agregados afetaria mais os processos de interação P-solo dependentes de tempo que os instantâneos. Agregados menores oferecem maior superfície de exposição, aumentando a adsorção, porém podem facilitar a dessorção de fosfatos (Camargo et al., 1979).

$\mathrm{O}$ fornecimento de nutrientes às plantas pode ser aumentado mantendo-se condições adequadas à difusão, tais como: tempo suficiente para permitir o deslocamento dos solutos do interior à superfície dos agregados e aumento da concentração dos solutos na solução do solo, o que se poderá conseguir com o uso de extratores com diferentes poderes de deslocar os íons do complexo de troca a exemplo da água, da solução de acetato de amônio 0,1 $\mathrm{mol} \mathrm{L}^{-1}$ a pH 7,0 e do extrator Mehlich-1. Desse ponto de vista, o tamanho dos agregados e a respectiva porosidade intra-agregados assumiriam importância destacada na disponibilidade de nutrientes, por determinarem a distância a ser percorrida pelos solutos em movimento e a sua interação com os sólidos das superfícies porosas.
O objetivo deste trabalho foi quantificar o teor de fósforo no efluente de diferentes classes de agregados de um Latossolo Vermelho distrófico, cultivado com milho por vários anos, em relação ao tempo de difusão, por meio de um experimento em colunas de solo, com utilização de água destilada, extrator Mehlich-1 e solução de acetado de amônio, como eluentes.

\section{MATERIAL E MÉTODOS}

No experimento realizado em laboratório com colunas de percolação, utilizaram-se quatro classes de agregados $\left(\mathrm{A}_{\mathrm{i}}\right)$ de um Latossolo Vermelho distrófico, cultivado com milho por mais de vinte anos. As amostras de solo foram coletadas de quatro unidades de amostragem diferentes, na área localizada no Centro Nacional de Pesquisa de Milho e Sorgo, Embrapa, município de Sete Lagoas, Estado de Minas Gerais, na camada de $0-5 \mathrm{~cm}$. Em cada bloco experimental utilizou-se material de um local de amostragem.

Após separação por via seca (EMBRAPA, 1979) as classes de agregados de 2,0 a $1,0\left(\mathrm{~A}_{1}\right)$, de 1,0 a $0,5\left(\mathrm{~A}_{2}\right)$, de 0,5 a 0,25 $\left(A_{3}\right)$ e de 0,25 a $0,105 \mathrm{~mm}\left(A_{4}\right)$ foram caracterizadas física e quimicamente (Tabela 1). A mineralogia da fração argila foi determinada usando-se amostras orientadas (Whitting, 1965) e um aparelho de raios X modelo Rigaku Geigerflex. Não houve variação qualitativa entre as classes de agregados, constituídas de caulinita, goethita, hematita, gibbsita e ilita.

Tabela 1. Caracterização química e física das diferentes classes de agregados do Latossolo Vermelho distrófico

\begin{tabular}{|c|c|}
\hline \multirow{2}{*}{ Característica } & Agregados (mm) \\
\hline & $1,0-0,5 \quad 0,5-0,25 \quad 0,25-0,105$ \\
\hline
\end{tabular}

\begin{tabular}{|c|c|c|c|c|}
\hline pH em água $(1: 2,5)$ & 5,20 & 5,10 & 5,10 & 5,00 \\
\hline $\mathrm{P}$ disponível $\left(\mathrm{mg} \mathrm{dm}^{-3}\right)^{1}$ & 5,80 & 6,50 & 7,20 & 8,30 \\
\hline \multicolumn{5}{|l|}{$\begin{array}{l}\text { Complexo sortivo } \\
\left(\mathrm{cmol}_{\mathrm{c}} \mathrm{dm}^{-3}\right)\end{array}$} \\
\hline $\mathrm{Mg}^{2+2}$ & 0,20 & 0,25 & 0,28 & 0,25 \\
\hline $\mathrm{Ca}^{2+2}$ & 0,72 & 0,75 & 0,85 & 0,90 \\
\hline $\mathrm{K}^{+1}$ & 0,19 & 0,21 & 0,21 & 0,21 \\
\hline $\mathrm{Al}^{3+2}$ & 1,22 & 1,28 & 1,50 & 1,50 \\
\hline $\mathrm{H}+\mathrm{Al}^{3+3}$ & 8,18 & 8,62 & 9,75 & 10,05 \\
\hline $\begin{array}{l}\text { Carbono orgânico } \\
\left(\operatorname{dag~kg}^{-1}\right)^{4}\end{array}$ & 2,50 & 2,80 & 3,20 & 3,30 \\
\hline \multicolumn{5}{|l|}{$\begin{array}{l}\text { Análise granulométrica } \\
\left(\mathrm{g} \mathrm{kg}^{-1}\right)\end{array}$} \\
\hline Areia ${ }^{5}$ & 310 & 250 & 170 & 140 \\
\hline Silte $^{5}$ & 160 & 200 & 270 & 240 \\
\hline Argila 5 & 530 & 550 & 560 & 620 \\
\hline \multicolumn{5}{|l|}{ Densidade $\left(\mathrm{kg} \mathrm{dm}^{-3}\right)$} \\
\hline Agregados $^{6}$ & 1,48 & 1,61 & 1,42 & 1,39 \\
\hline Partículas $^{7}$ & 2,50 & 2,56 & 2,52 & 2,47 \\
\hline
\end{tabular}

${ }^{1}$ Extrator Mehlich-1 (Vettori, 1969)

${ }^{2}$ Extrator KCl $1 \mathrm{~mol} \mathrm{~L}^{-1}$ (Vettori, 1969)

${ }^{3}$ Extrator acetato de cálcio (Vettori, 1969)

${ }^{4}$ Método de Walkley \& Black (Jackson, 1958)

${ }^{5}$ Método da pipeta (EMBRAPA, 1979)

${ }^{6}$ Método do cimento em pó (Ruiz et al., 1994)

${ }^{7}$ Método do balão volumétrico (EMBRAPA, 1979)

Foram realizados três ensaios com utilização de água destilada, extrator Mehlich-1 ( $\mathrm{HCl} 0,05$ mol L-1 $+\mathrm{H}_{2} \mathrm{SO}_{4} 0,0125$ mol L-1) e solução de acetato de amônio $0,1 \mathrm{~mol} \mathrm{~L}^{-1}$, a pH 7 , 
como eluentes. Os tratamentos, dispostos em um delineamento em blocos casualizados com quatro repetições, corresponderam a um arranjo fatorial $4 \times 5$, constituído pelas quatro classes de agregados mencionadas anteriormente e cinco diferentes tempos de difusão $(0,1,2,4$ e 6 dias $)$ contados a partir do término da saturação das colunas. As eluições nas colunas de solo foram realizadas, por cinco vezes, em intervalos de tempo iguais aos estabelecidos para a ocorrência da difusão.

A unidade experimental foi constituída de um cilindro de vidro de $2 \mathrm{~cm}$ de diâmetro interno e $30 \mathrm{~cm}$ de comprimento, cuja extremidade inferior, afunilada, foi preenchida com lã de vidro, para evitar perda de material de solo. Uma mangueira plástica, munida de um regulador de vazão, semelhante àquele de soro hospitalar, foi inserida na extremidade afunilada, a fim de proporcionar o controle da velocidade média de escoamento nas colunas com os agregados maiores e, assim, deixá-la próximo àquela da coluna preenchida com os agregados de menor tamanho. A velocidade de escoamento nas colunas foi mantida aproximadamente constante, durante as cinco eluições executadas.

Essas colunas foram preenchidas com agregados até os $5 \mathrm{~cm}$ da borda superior e os materiais cobertos com lã de vidro, para evitar o impacto direto do eluente sobre os agregados. A seguir, as colunas foram fixadas verticalmente numa estrutura apropriada e saturadas com o eluente no sentido ascendente, para diminuir ao máximo a presença de ar nos poros, usando-se um conjunto de alimentação automático (frasco de Mariotte); posteriormente, o sistema de alimentação foi interligado à extremidade superior da coluna, possibilitando o início do movimento vertical descendente, em meio saturado, com o eluente.

As unidades experimentais correspondentes ao tempo de difusão zero receberam, de uma só vez, todo o volume de eluente correspondente a dez volumes de poros do material da coluna. O efluente foi coletado continuamente em cinco frações de dois volumes de poros. O volume de poros do solo na coluna foi estimado empregando-se $V_{\mathrm{P}}=\pi \mathrm{r}^{2} \mathrm{~h}\left(1-\mathrm{D}_{\mathrm{S}} / \mathrm{D}_{\mathrm{P}}\right)$ em que ré o raio interno da coluna, $\mathrm{h}$ a altura do solo na coluna, $\mathrm{D}_{\mathrm{S}} \mathrm{a}$ densidade determinada pelo método da proveta (EMBRAPA, 1979) e $D_{\mathrm{p}}$ a densidade das partículas (Tabela 1).

Nas unidades experimentais restantes, após decorrido o tempo de difusão estabelecido para cada tratamento, foram realizadas eluições, totalizando dois volumes de poros de efluente, numa única amostra. Este procedimento foi repetido nos intervalos correspondentes a cada tratamento, até totalizar cinco eluições e dez volumes de poros lixiviados.

Cada fração de dois volumes de poros de efluente foi acondicionada em recipiente plástico, com tampa de pressão, e congelada. Na finalização do ensaio, determinou-se a concentração do fósforo no efluente, colorimetricamente, após formação do complexo fosfomolíbdico reduzido (Braga \& Defelipo, 1974). Considerando-se a concentração de fósforo e o volume lixiviado, calculou-se a quantidade de fósforo retirada por fração de efluente.

Após a última eluição, os agregados de cada coluna foram secados ao ar e desagregados em almofariz. Neste material determinou-se o teor de fósforo, utilizando-se o extrator Mehlich-1.

Os resultados foram analisados estatisticamente, desdobrando-se os graus de liberdade referentes às classes de agregados, em contrastes ortogonais. A resposta ao tempo de difusão, dentro de cada classe de agregado, foi analisada por regressão.

\section{RESULTADOS E DISCUSSÃO}

Nas três primeiras lixiviações com água destilada, o eluente retirou menos fósforo dos agregados maiores $\left(A_{1}\right)$ (Tabela 2); esta tendência também foi registrada nas duas últimas lixiviações, sendo evidenciada pelos valores negativos dos contrastes que comparam $\mathrm{A}_{1}$ com as outras classes de agregados não alcançando, contudo, significância estatística (Tabela 2).

Tabela 2. Quantidade de fósforo no efluente após lixiviações com dois volumes de poros $\left(\mathrm{L}_{\mathrm{i}}\right)$ considerando-se a classe de agregados, para eluições com água destilada e com extrator Mehlich-1

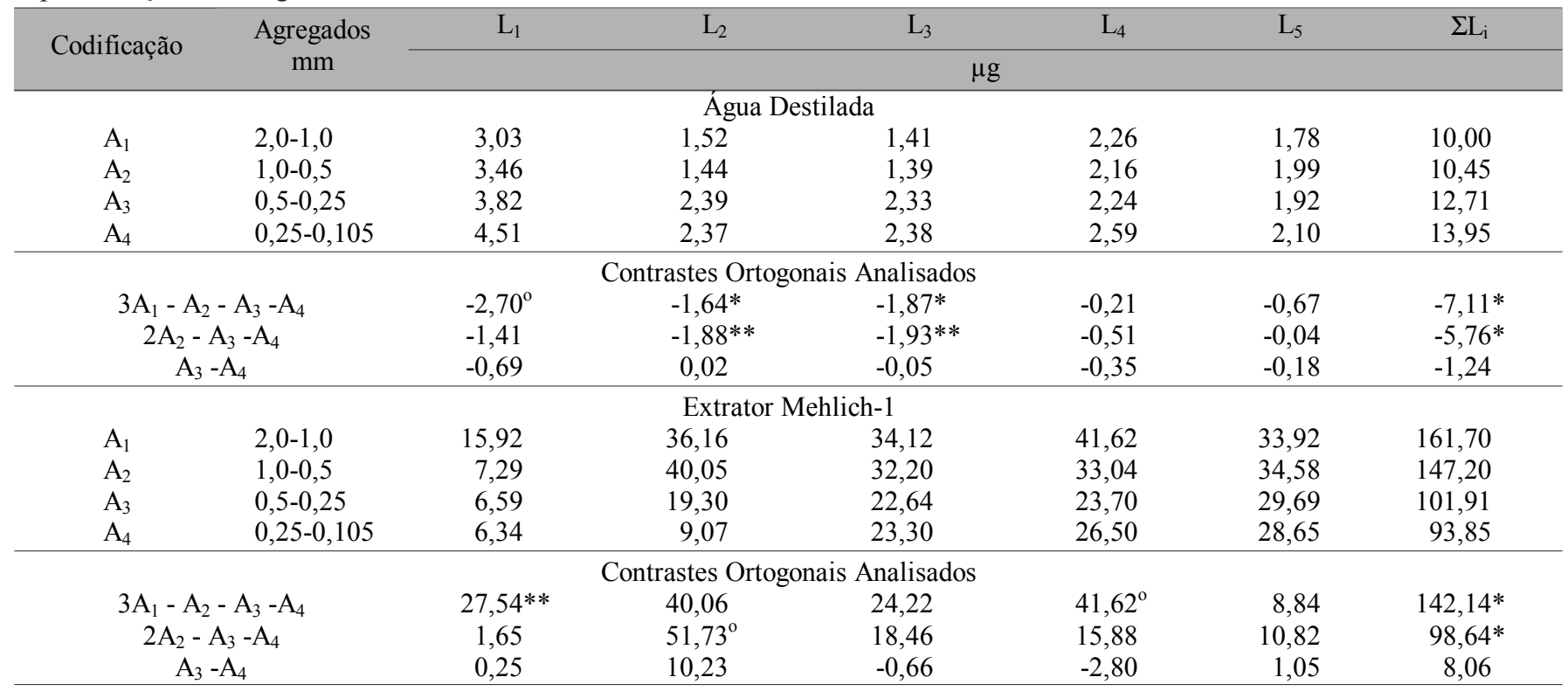

${ }^{\circ},{ }^{*} \mathrm{e}^{* *}$ : Significativo aos níveis de 10,5 e $1 \%$, respectivamente, pelo teste $\mathrm{F}$ 
A água destilada também extraiu menos fósforo de $\mathrm{A}_{2}$, comparativamente a $\mathrm{A}_{3}$ e $\mathrm{A}_{4}$, confirmando que esse eluente retirou mais fósforo dos agregados menores, acompanhando a maior disponibilidade de fósforo em agregados menores, evidenciada na caracterização das amostras (Tabela 1). Moura Filho \& Buol (1976) também mostraram, em agregados de um Latossolo Roxo, que há maior disponibilidade de fósforo com a redução do tamanho do agregado.

As mesmas diferenças não foram observadas quando da comparação do fósforo lixiviado das colunas contendo os agregados $\mathrm{A}_{3}$ e $\mathrm{A}_{4}$ (Tabela 2). As diferentes classes de agregados apresentaram raios médios de 1,$5 ; 0,75 ; 0,375$ e $0,1775 \mathrm{~mm}$, respectivamente, indicando que a máxima distância média a ser percorrida do interior do agregado até a solução móvel, em resposta a um gradiente menor de concentração nos agregados maiores, afetou negativamente a difusão de fósforo, cujo comportamento foi minorado nos agregados $\mathrm{A}_{3}$ e $\mathrm{A}_{4}$, onde o menor percurso resultou num gradiente maior de concentração e na maior difusão de fósforo.

Observa-se, na Tabela 2, que a quantidade total de fósforo no lixiviado $\left(\mathrm{T}=\Sigma \mathrm{L}_{\mathrm{i}}\right)$ está associada principalmente à primeira lixiviação, sem dúvida por retirar a maior parte do fósforo da superfície dos agregados. Esta dependência foi mais marcante nos agregados maiores, que apresentaram a menor superfície específica externa em contato direto com a solução móvel, além de um raio maior de agregados, que implicou num gradiente menor de concentração de fósforo. O histórico da área, com adubações sucessivas por mais de vinte anos, justifica a maior adsorção de fósforo na superfície dos agregados.

As análises de variância dos resultados experimentais apresentaram, em geral, elevados coeficientes de variação atribuídos, fundamentalmente, às baixas concentrações de fósforo nos efluentes e à heterogeneidade entre áreas amostradas. A conseqüência foi a não-significância, em níveis correntemente utilizados, de alguns coeficientes das equações de regressão, quando corrigidos utilizando-se o quadrado médio do resíduo da análise de variância (Alvarez, 1991). Para melhor explicitar os fenômenos observados e evitar perda de informação, optou-se pela escolha dos modelos de regressão que apresentassem o maior coeficiente de determinação ajustado, independentemente da significância de seus coeficientes (Figura 1).

De maneira geral, a quantidade de fósforo no efluente, aumentou com o tempo de difusão, independentemente do tamanho dos agregados (Figura 1). Observa-se que os agregados menores $\left(\mathrm{A}_{3}\right.$ e $\left.\mathrm{A}_{4}\right)$ perderam, até a terceira lixiviação, mais fósforo que os maiores, independentemente do tempo de difusão; no entanto, nas duas últimas lixiviações tenderam a igualar-se nos maiores tempos de contato agregados-eluente.

Este comportamento seria conseqüência da baixa capacidade da água em deslocar o fósforo do complexo e/ou, solubilizar formas precipitadas, o que levaria a estabelecer um gradiente de concentração mínimo entre a solução móvel e a imóvel. Nas primeiras lixiviações, retirar-se-ia o fósforo mais próximo à superfície dos agregados, condição facilitada nos de menor tamanho, em virtude da maior proporção de superfícies adsorventes. Nas últimas lixiviações e para os maiores tempos de difusão, a maior concentração de fósforo residente no centro dos agregados, resultou num aumento no gradiente de
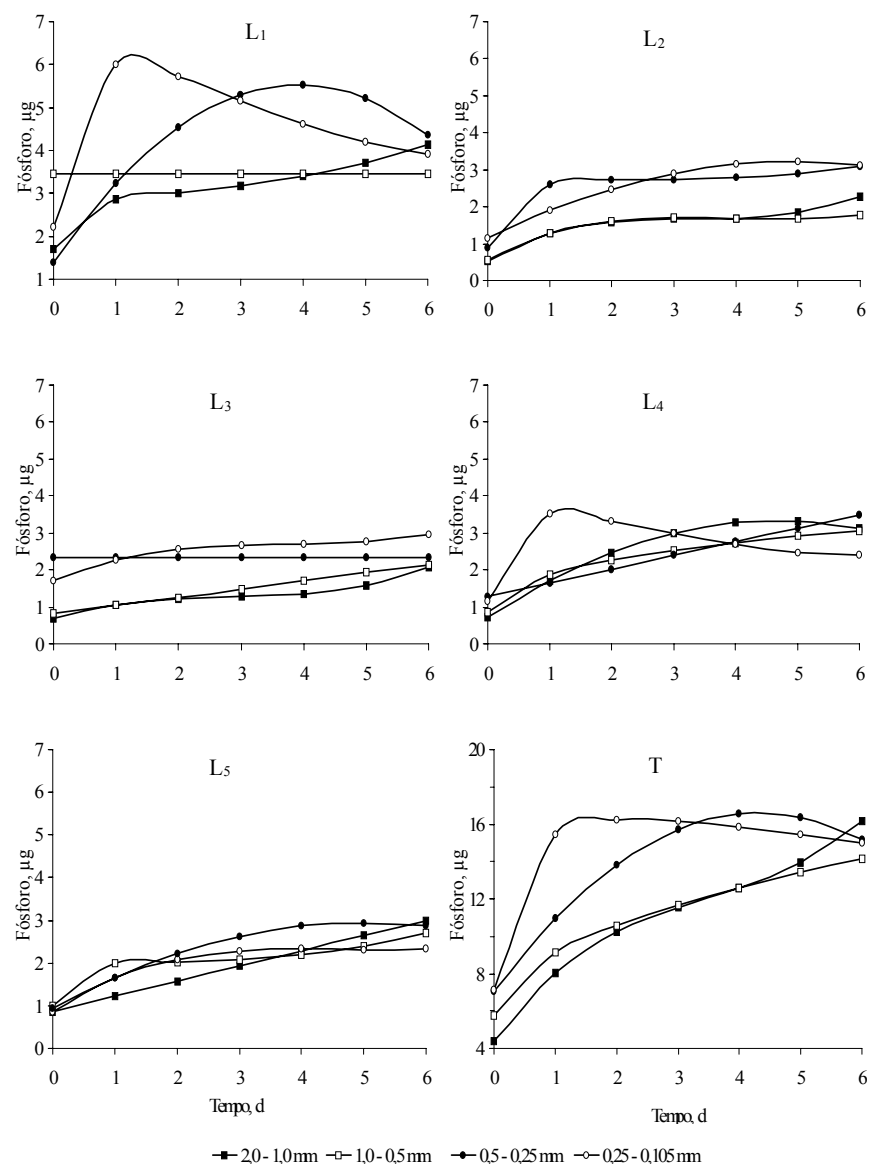

Figura 1. Quantidade de fósforo no efluente após lixiviações com dois volumes de poros $\left(\mathrm{L}_{\mathrm{i}}\right)$ e quantidade total de fósforo $\left(\mathrm{T}=\sum \mathrm{L}_{\mathrm{i}}\right)$ em relação ao tempo de difusão, considerando-se a classe de agregados, para eluições com água destilada

concentração e numa interação fósforo-colóide menor, fazendo com que as maiores distâncias a serem percorridas até a superfície dos agregados em $\mathrm{A}_{1}$ e $\mathrm{A}_{2}$ fossem menos relevantes, permitindo a eluição de maiores quantidades de fósforo em relação aos agregados $\mathrm{A}_{3}$ e $\mathrm{A}_{4}$. Isto sugere que, havendo tempo suficiente para difusão, os agregados de maior tamanho se equivaleriam ou superariam os pequenos, quanto à liberação de fósforo para a solução externa.

Na primeira eluição com o extrator Mehlich-1, a quantidade de fósforo extraída apresentou comportamento inverso ao das eluições com água destilada, verificando-se maiores valores nos agregados de maior tamanho, comparativamente aos menores (Tabela 2). Esta tendência foi mantida nas lixiviações posteriores, como evidenciado pelo sinal positivo dos valores dos contrastes ortogonais. A quantidade total de fósforo, significativamente maior nos agregados de maior tamanho, confirmou este comportamento, uma vez que $\mathrm{T}$ expressa o efeito acumulativo das respostas individuais.

A quantidade de fósforo eluída pelo extrator Mehlich-1, maior nos agregados maiores, estaria relacionada ao diâmetro médio dos poros intra-agregados e à interação entre o fósforo e os colóides inorgânicos. Os teores mais elevados de areia e menores de argila, determinados nos agregados de maior tamanho, indicariam a existência de poros maiores, permitindo maior fluxo intra-agregado e menor poder de adsorção do 
fósforo, permitindo a maior solubilização de fósforo por um fluido deslocador com apreciável capacidade de dissolução, como o extrator Mehlich-1 e, conseqüentemente, incrementa seu transporte (Tabela 1).

Horn et al. (1994) sugeriram que o transporte de íons por fluxo de massa e por difusão é menor nos poros pequenos e mais tortuosos. Por extensão, nos Latossolos o transporte se verificaria, em ordem decrescente, nos poros interagregados e nos poros intra-agregados. Nesses últimos, o decréscimo acompanharia o tamanho do agregado, cujo comportamento foi verificado nas eluições com extrator Mehlich-1, que apresenta elevada capacidade de extração. Quando usada água destilada, as quantidades extraídas foram sensivelmente inferiores, e o fósforo, deslocado até a superfície do agregado, governaria a concentração no lixiviado.

Aceitando-se a ocorrência de solução semimóvel intraagregado, presente em maior proporção naqueles de maior tamanho, os resultados alcançados com extrator Mehlich-1 sugerem um modelo de distribuição do fósforo nos agregados, em que a maior parte do fósforo lábil se encontra na região intra-agregado. Conseqüentemente, pequena proporção do total de fósforo estaria na superfície dos agregados; tal constatação destaca a importância do transporte para a absorção de fósforo, fazendo-a dependente da distância (tamanho de agregados) do tempo de difusão, da geometria do meio poroso (inter e intra-agregados) e da reatividade das partículas sólidas dos constituintes dos agregados (Kunishi \& Taylor, 1975; Nye, 1979). A associação de argilas com maior retenção de fósforo pelo solo tem sido exaustivamente descrita na literatura científica (Goldberg \& Sposito, 1985).

Outra característica que mostra a diferença entre os dois eluentes é o fato da quantidade de fósforo no efluente diminuir com as eluições, quando utilizada a água destilada, e aumentar nas colunas tratadas com extrator Mehlich-1 (Tabela 2). Nas amostras utilizadas, supõe-se que o fósforo estaria prioritariamente ligado a alumínio e ferro, em compostos de baixíssima solubilidade. O baixo $\mathrm{pH}$ do extrator Mehlich-1, próximo de 1,12, favoreceu a dissolução parcial das formas precipitadas de fósforo, incrementando o teor de fósforo em solução (Kamprath \& Watson, 1980).

Contrariamente aos resultados obtidos com água destilada nas eluições realizadas com extrator Mehlich-1, a quantidade de fósforo retirada do sistema decresceu com o tempo de difusão, independentemente do tamanho dos agregados (Figura 2). Verificou-se, também, que a quantidade de fósforo lixiviada de $A_{1}$ e $A_{2}$, para qualquer tempo superior a um dia, foi superior àquela obtida em $\mathrm{A}_{3}$ e $\mathrm{A}_{4}$, mostrando comportamento oposto ao da disponibilidade inicial de fósforo nos agregados (Tabela 1).

As quantidades de fósforo mais elevadas no tempo de difusão zero (Figura 2), indicam que o extrator Mehlich-1 promoveria rápida solubilização dos compostos precipitados de fósforo. Nesse tratamento passaram-se, ininterruptamente, dez volumes de poros do eluente, o que levou a uma contínua remoção da solução interagregados, aumentando o gradiente de concentração entre a solução imóvel intra-agregados e a solução móvel interagregados favorecendo, assim, o transporte do íon fosfato, como indicado pela Lei de Fick.
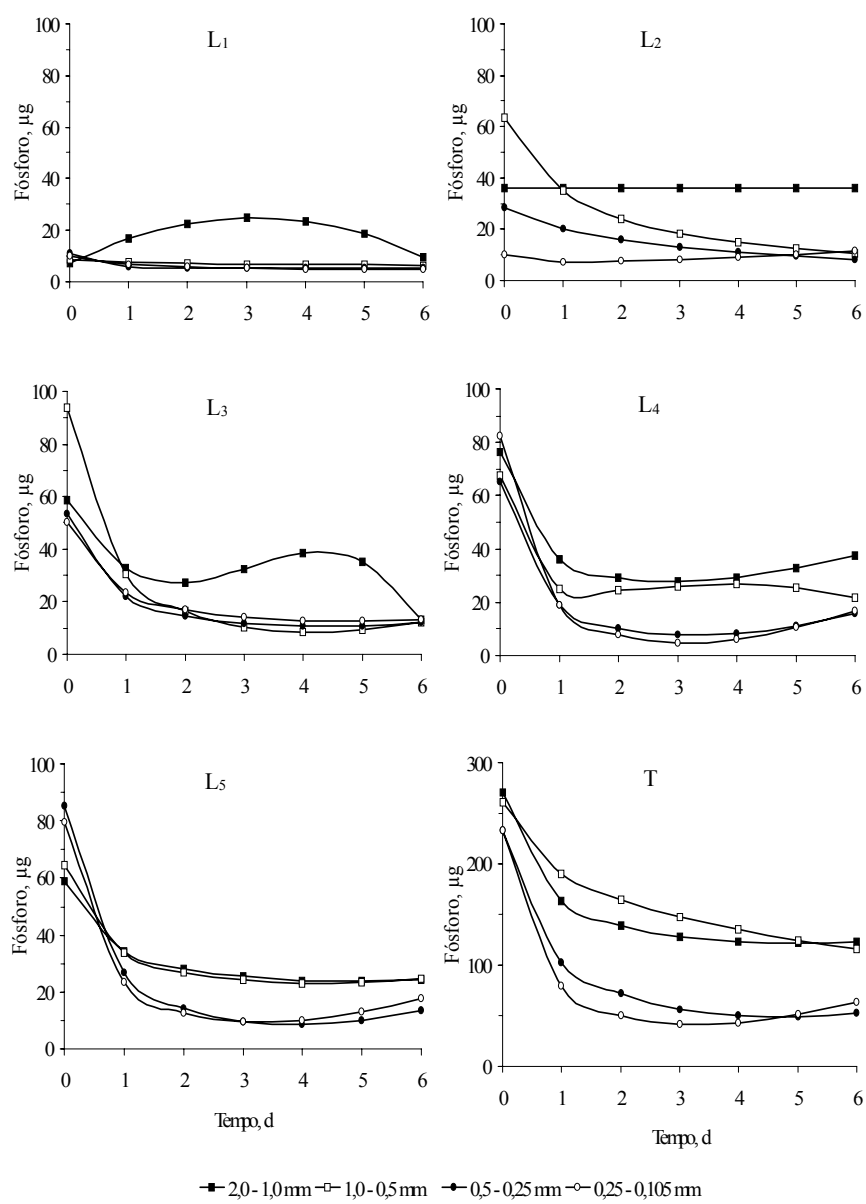

Figura 2. Quantidade de fósforo no efluente após lixiviações com dois volumes de poros $\left(\mathrm{L}_{\mathrm{i}}\right)$ e quantidade total de fósforo $\left(\mathrm{T}=\sum \mathrm{L}_{\mathrm{i}}\right)$ em relação ao tempo de difusão, considerando-se a classe de agregados, para eluições com extrator Mehlich-1

O decréscimo da quantidade de fósforo, eluída com o tempo pode ser atribuído ao estabelecimento de um gradiente menor de concentração, em comparação com aquele do tempo zero. A não-remoção do eluente promoveria redução do gradiente de concentração entre as soluções móvel e imóvel, que resultaria num transporte mais lento.

As quantidades de fósforo eluídas com solução de acetato de amônio não atingiram o mínimo necessário para permitir sua detecção pelo método analítico e instrumental utilizado. Esta baixa concentração de fósforo pode ser atribuída ao $\mathrm{pH} 7 \mathrm{da}$ solução deslocadora, que provocou a diminuição da solubilidade dos fosfatos.

Os teores de fósforo disponível (Mehlich-1) nos materiais desagregados, após lixiviações com água destilada, não diferiram entre as classes de agregados (Tabela 3 ) e, tampouco, houve diferenças para o tempo de difusão (Tabela 4). Os teores médios de fósforo registrados, muito próximos àqueles da caracterização (Tabela 1), indicam que a quantidade de fósforo eluída pela água destilada, por ter sido pequena, não influenciou a disponibilidade de fósforo pelo extrator Mehlich-1, na determinação preliminar e posterior ao ensaio.

Os valores elevados do fósforo disponível após lixiviações com o extrator Mehlich-1 (Tabela 3), praticamente dobrando àqueles da caracterização (Tabela 1), evidenciam a capacidade 
da solução ácida $\left(\mathrm{HCl} \mathrm{0,05} \mathrm{mol} \mathrm{L-1}+\mathrm{H}_{2} \mathrm{SO}_{4} 0,0125 \mathrm{~mol} \mathrm{~L}^{-1}\right)$ de provocar a reversão de formas não-lábeis em formas lábeis. Esta característica é comprovada pela relação direta entre a disponibilidade de fósforo e o tempo de contato agregadossolução ácida, como evidenciado nas equações de regressão mostradas na Tabela 4.

Tabela 3. Teores de fósforo (Mehlich-1) nos materiais desagregados, após as lixiviações, considerando-se o eluente utilizado, a classe de agregados e o tempo de difusão ${ }^{1}$

\begin{tabular}{lcccccc}
\hline \multirow{7}{*}{$\begin{array}{c}\text { Agregados } \\
\text { mm }\end{array}$} & 0 & 1 & 2 & 4 & 6 & Média \\
\cline { 2 - 6 } & \multicolumn{7}{c}{ mg dm $^{-3}$} \\
& \multicolumn{7}{c}{ Água Destilada } \\
$2,0-1,0$ & 7,53 & 7,32 & 6,69 & 7,50 & 7,11 & 7,23 \\
$1,0-0,5$ & 7,01 & 6,90 & 6,56 & 7,37 & 7,11 & 6,99 \\
$0,5-0,25$ & 6,82 & 7,53 & 7,32 & 7,37 & 7,74 & 7,36 \\
$0,25-0,105$ & 7,50 & 6,69 & 7,84 & 7,50 & 6,46 & 7,20 \\
\hline \multicolumn{7}{c}{ Extrator Mehlich-1 } \\
$2,0-1,0$ & 12,25 & 14,71 & 15,46 & 18,10 & 19,27 & 15,96 \\
$1,0-0,5$ & 12,62 & 13,82 & 14,26 & 17,55 & 20,73 & 15,80 \\
$0,5-0,25$ & 13,84 & 17,21 & 14,60 & 19,14 & 22,09 & 17,38 \\
$0,25-0,105$ & 14,16 & 16,52 & 18,30 & 19,92 & 16,04 & 16,99 \\
\hline${ }^{1}$ Não houve diferenças estatisticamente significativas em nivvel de 5\% pelo teste F, entre classes de \\
agregados, dentro de cada tempo de difusão
\end{tabular}

Tabela 4. Equações de regressão relacionando a disponibilidade de fósforo (Mehlich-1) após as lixiviações, nos materiais desagregados, em $\mathrm{mg} \mathrm{dm}^{-3}$, com o tempo de difusão (D), em dias, considerando-se o eluente utilizado e a classe de agregados

\begin{tabular}{lcc}
$\begin{array}{c}\text { Agregados } \\
\mathrm{mm}\end{array}$ & Equação de Regressão & $\mathrm{R}^{2}$ \\
\hline \multicolumn{3}{c}{ Água Destilada } \\
$2,0-1,0$ & $\hat{\mathrm{Y}}=\overline{\mathrm{Y}}=7,23$ \\
$1,0-0,5$ & $\hat{\mathrm{Y}}=\overline{\mathrm{Y}}=6,99$ \\
$0,5-0,25$ & $\hat{\mathrm{Y}}=\overline{\mathrm{Y}}=7,36$ \\
$0,25-0,105$ & $\hat{\mathrm{Y}}=\overline{\mathrm{Y}}=7,20$ \\
\hline \multicolumn{3}{c}{ Extrator Mehlich-1 } \\
$2,0-1,0$ & $\hat{\mathrm{Y}}=13,02+1,13^{* *} \mathrm{D}$ \\
$1,0-0,5$ & $\hat{\mathrm{Y}}=12,25+1,36^{* *} \mathrm{D}$ & 0,951 \\
$0,5-0,25$ & $\hat{\mathrm{Y}}=14,06+1,28^{* *} \mathrm{D}$ \\
$0,25-0,105$ & $\hat{\mathrm{Y}}=13,91+3,36^{*} \mathrm{D}-0,50^{*} \mathrm{D}^{2}$ & 0,830 \\
*e $\mathrm{e}$ * significativo aos niveis de $5 \mathrm{e} 1 \%$, respectivamente, pelo Teste t
\end{tabular}

\section{CONCLUSÕES}

1. A água destilada eluiu maior quantidade de fósforo dos agregados de menor tamanho, observando-se incremento da quantidade de fósforo eluído, com o tempo de difusão.

2. O extrator Mehlich-1 eluiu de três a sessenta vezes mais fósforo que a água destilada, mostrando comportamento inverso em relação à classe de agregados e ao tempo de contato.

3. As concentrações de fósforo eluídas com solução de acetato de amônio não atingiram o mínimo necessário para permitir sua detecção.

\section{LITERATURA CITADA}

Alvarez, V.V.H. Avaliação da fertilidade do solo (superfícies de resposta - modelos aproximativos para expressar a relação fator-resposta). Viçosa: Universidade Federal de Viçosa, 1991. 75p. Boletim 228

Braga, J.M.; Defelipo, B.V. Determinação espectro-fotométrica de fósforo em extratos de solo e material vegetal. Revista Ceres, Viçosa, v.21, p.73-85, 1974.

Camargo, O.A.; Biggar, J.W.; Nielsen, D.R. Transport of inorganic phosphorus in an Alfisol. Soil Science Society of America Journal, Madison, v.43, p.884-890, 1979.

EMBRAPA - Empresa Brasileira de Pesquisa Agropecuária. Manual de métodos de análise de solo. Rio de Janeiro: Serviço Nacional de Levantamento e Conservação de Solos, 1979.

Goldberg, S.; Sposito, G. On the mechanism of specific phosphate adsorption by hydroxilated mineral surfaces: A review. Communications in Soil Science and Plant Analysis, Athens, v.16, p.801-821, 1985.

Gupta, A.; Destouni, G.; Jensen, M.B. Modelling tritium and phosphorus transport by preferential flow in structured soil. Journal of Contaminant Hydrology, v.35, n.4, p.389-407, 1999.

Horn, R.; Taubner, H.; Wuttke, M.; Baumgartl, T. Soil physical properties related to soil structure. Soil \& Tillage Research, Amsterdam, v.30, p.187-216, 1994.

Jackson, M.L. Soil chemical analysis. New Jersey: PrenticeHall, 1958. 498p.

Kamprath, E.J.; Watson, M.E. Conventional soil and tests for assessing the phosphorus status of soil. In: Khasawneh, F.E.; Sample, E.C.; Kamprath, E.J. (eds.). The role of phosphorus in agriculture. Madison: American Society of Agronomy, Crop Science Society of America, Soil Science Society of America, 1980. p.433-469.

Kunishi, H..M.; Taylor, A.W. Effect of phosphate applications on the diffusion coefficients and available phosphate in an acid soil. Journal of Soil Science, Oxford, v.26, p.267-277, 1975.

Moura Filho, W.; Buol, S.W. Studies of a Latosol Roxo (Eutrutox) in Brazil: Micromorphology effect on ion release. Experientiae, Viçosa, v.21, p.161-177, 1976.

Nye, P.H. Diffusion of ions and uncharged solutes in soils and soil clays. Advances in Agronomy, New York, v. 31, p.225-272, 1979.

Passioura, J.B. Hydrodynamic dispersion in aggregated media. I. Theory. Soil Science, Baltimore, v.111, p.339-344, 1971.

Rao, P.S.C.; Jessup, R.E.; Rolston, D.E.; Davidson, J.M.; Kilcrease, D.P. Experimental and mathematical description of non adsorbed solute transfer by diffusion in spherical aggregates. Soil Science Society of America Journal, Madison, v.44, p.684-688, 1980.

Ruiz, H.A.; Alves, J.F.O.; Martins, L.G.C. Densidade de agregados separados dos horizontes A e B de um LV e de um PVc. In: Reunião Brasileira de Manejo e Conservação do Solo e da Água, 10., 1994, Florianópolis. Anais... Florianópolis: Sociedade Brasileira de Ciência do Solo, 1994. p.332-333. 
van Genuchten, M.Th.; Wierenga, P.J. Mass transfer studies in sorbing porous media: 1. Analytical solutions. Soil Science Society of America Journal, Madison, v.40, p.473-480, 1976.

Vettori, L. Métodos de análise de solo. Rio de Janeiro: EPE, Ministério da Agricultura, 1969.24p. Boletim Técnico, 7
Whitting, L.D. X-ray diffraction techniques for mineral identification and mineralogical composition. In: Black, C.A. (ed.). Methods of soil analysis. Part 1. Physical and mineralogical properties, including statistics of measurement and sampling. Madison: American Society of Agronomy, Soil Science Society of America, 1965. p.671-698. Agronomy Series, 9 